\title{
LOCATION, ORIENTATION AND DYNAMICS OF TWO MOLECULES WITH MITOCHONDRIAL ACTIVITY DISSOLVED IN ANIONIC LYOMESOPHASE. $A^{2}$ H-NMR AND MD STUDY
}

\author{
VÍCTOR E. BAHAMONDE-PADILLA', MAXIMILIANO MARTÍNEZ-CIFUENTES ${ }^{2}$, \\ DANIEL MUÑOZ-MASSON ${ }^{1}$, ÁLVARO RUIZ', HERNÁN AHUMADA ${ }^{3}$, RAMIRO ARAYA-MATURANA ${ }^{2}$, JORGE \\ SOTO-DELGADO', AND BORIS E. WEISS-LÓPEZ ${ }^{*}$
}

\author{
${ }^{1}$ Universidad de Chile, Facultad de Ciencias, Departamento de Química, Casilla 653, Santiago, Chile. \\ ${ }^{2}$ Universidad de Chile, Facultad de Ciencias Químicas y Farmacéuticas, Departamento de Química Orgánica y Fisicoquímica, Casilla 233, Santiago 1, Chile. \\ ${ }^{3}$ University of Glasgow, School of Chemistry, Glasgow G12 8QQ, U.K. \\ ${ }^{4}$ Universidad Técnica Federico Santa María, Departamento de Química, Casilla 110-V, Valparaíso, Chile.
}

(Received: March 7, 2012 - Accepted: April 25, 2012)

\begin{abstract}
4,4-Dimethyl-5,8-dihydroanthracene-1,9,10(4H)-trione (Q1) and 9,10-Dihydroxy-4,4-dimethyl-5,8-dihydro-1(4H)-anthracenone (Q2), two molecules that inhibit cancer cell respiration, were selectively deuterated and dissolved in an anionic discotic nematic lyotropic liquid crystal (dnllc) solution. The solution provides a magnetic field oriented anisotropic medium, where the location, average orientation and dynamics of Q1 and Q2 were examined by measuring ${ }^{2} \mathrm{H}-\mathrm{NMR}$ quadrupole splittings $\left(\Delta v_{0}\right)$ and ${ }^{2} \mathrm{H}$ longitudinal relaxation times $\left(\mathrm{T}_{1}\right)$. The NMR data shows that both molecules are strongly attached to the aggregate and, when dissolved, increase the alignment of the interface components with the magnetic field. However they present different average orientations. To assist with the interpretation of the experimental results, 300ns Molecular Dynamics (MD) trajectories of a bilayer model of the aggregate were calculated. The results show that both molecules spontaneously diffuse inside the bilayer, to locate in the limit between the hydrophobic core and the interface. The orientations of both molecules in the aggregate are determined by the formation of H-bonds with water.
\end{abstract}

Keywords. Quinones, Hydroquinones, Deuterium Quadrupole Splitting, Longitudinal Relaxation Time, Lyomesophase.

\section{INTRODUCTION}

Polyphenols are usually recognized by their anti-oxidant capabilities; however in certain conditions they can also function as pro-oxidants. ${ }^{1-4}$ Hydroquinones belong to this class of compounds and they are among the strongest anti-oxidants. ${ }^{5}$ The reduction of quinones and the oxidation of hydroquinones have been related to cytotoxicity and anti-cancer activity. ${ }^{6-8}$ Besides, it is known that quinone derivatives display a variety of biological activities, including fungicidal, through the formation of semi-quinone radicals. ${ }^{9}$ In the past, significant work of our group has been devoted to the synthesis, mechanism of formation and biological evaluation of quinones and hydroquinones. ${ }^{10-12}$ Biological activity of these products has been measured trough $\mathrm{IC}_{50}$ values against tumor cell respiration of TA3 cell line and TA3MTX-R multidrug resistant variety. ${ }^{13}$

It is now accepted that mitochondria are involved in cell apoptosis. Malfunction of mitochondria involves lack of apoptosis and this has been related to cancer etiology. ${ }^{14}$ Mitochondria have been considered an important target for cancer therapy, and quinones and hydroquinones are believed to function inside the mitochondria. ${ }^{15-17}$ Therefore, there is no doubt that in order to reach their targets these molecules must cross several membranes, including mitochondrial membranes. On the other hand, it is well known that in-vivo antioxidant activity of polyphenols is limited by their ability to cross membranes.

The interaction between biologically active molecules and bilayers has been a very active field of research. In the past we examined counter-ion effects and dynamical behavior of parathion, a well known pesticide, dissolved in anionic and cationic mesophases. ${ }^{18,19}$ Inclusion of the pesticide in a cationic mesophase increases the order degree of the interface components; on the other hand, when dissolved in anionic mesophases, the effect is strongly dependent on the nature of the counter-ion. Work in a similar field using several spectroscopic techniques has shown the existence of a preferential interaction between quinolone derivatives and negatively charged phospholipids vesicles ${ }^{20,21}$ evidencing again the importance of the amphiphilic head-group properties. Therefore, increased knowledge about the distribution, average orientation, interactions and dynamics of biologically active molecules, when they are dissolved in an amphiphilic bilayer, a simple model of membrane, provides valuable information for a better understanding of drug functioning and rational drug design.

In this article we study the average orientation, distribution and dynamics of two structurally related molecules, a quinone and its reduced form, the corresponding hydroquinone, which were selected from our previous work.
The molecules are 4,4-dimethyl-5,8-dihydroanthracene-1,9,10(4H)-trione (Q1) and 9,10-dihydroxy-4,4-dimethyl-5,8-dihydro-1 (4H)-anthracenone (Q2). They were selectively deuterated at positions 5, 6, 7 and 8 (see figure 1), and dissolved in anionic discotic nematic lyotropic liquid crystal (dnllc) solution. Despite their apparent structural similarity these two molecules show different anti-cancer activity: Q2 is two to three times more active than Q1 as a tumor cell respiration inhibitor $\left(\mathrm{IC}_{50} \mathrm{Q} 1=0.22 \pm 0.02 \mathrm{mM}\right.$ and $\mathrm{IC}_{50} \mathrm{Q} 2=0.08 \pm 0.01 \mathrm{mM}$ against TA3 cell line; $\mathrm{IC}_{50} \mathrm{Q} 1=0.17 \pm 0.02 \mathrm{mM}$ and $\mathrm{IC}_{50} \mathrm{Q} 2=0.07 \pm 0.01 \mathrm{mM}$ against the TA3-MTX-R variety) $(12,13)$. In general, $\mathrm{IC}_{50}$ for oxygen uptake inhibition are about an order of magnitude greater than $\mathrm{IC}_{50}$ for cytotoxicity; however, it is a quick test for preliminary screening of possible anti-cancer activity. For instance, Q2 exhibits low micromolar dose-dependent growth inhibition of the human U937 tumor cell line (human monocytic leukemia), $\mathrm{IC}_{50}=7.96 \mu \mathrm{M}^{12}$<smiles>CC1(C)C=CC(=O)C2=C1C(=O)C1=C(CC=CC1)C2=O</smiles>

Q1<smiles>CC1(C)C=CC(=O)c2c(O)c3c(c(O)c21)CC=CC3</smiles>

Q2
Figure 1. Structures of the studied molecules.

The dnllc is prepared by dissolving cesium decylsulfate (CsDS), decanol (DeOH, 20\% DeOH-a-d $\left.\mathrm{d}_{2}\right)$ and $\mathrm{Cs}_{2} \mathrm{SO}_{4}$ in water $\left(0.1 \% \mathrm{D}_{2} \mathrm{O}\right)$ and consist of a concentrated solution of disc-shaped aggregates, like flat micelles, made of decylsulfate ions and DeOH. In the presence of an applied magnetic field they spontaneously orient with the symmetry axis of the oblate perpendicular to the field direction, providing an anisotropic medium. This property makes these systems particularly suitable to be studied by NMR of quadrupolar nuclei. ${ }^{2} \mathrm{H}-\mathrm{NMR}$ quadrupolar splittings $\left(\Delta v_{\mathrm{O}}\right)$ and longitudinal relaxation times $\left(\mathrm{T}_{1}\right)$ were measured for all deuterium nucleus in all samples. Since the structures 
of Q1 and Q2 are significantly rigid, $\Delta v_{0}$ and $T_{1}$ adequately represent the dynamics of the complete molecules. NMR quadrupolar splittings arise from the quadrupolar interaction that occurs between nuclei with spin quantum number I $\geq 1$, like deuterium, and the electric field gradient it experiences. The measured value of $\Delta v_{Q}$ depends on the average orientation and dynamics of the principal axis of the electric field gradient, (the direction of the C-D bond for all practical purposes), with respect to the magnetic field direction. On the other hand, $\mathrm{T}_{1}$ of quadrupolar nuclei is dominated by fluctuations in the quadrupolar interaction, due to the Brownian motion experienced by the principal axis of the electric field gradient in the magnetic field. Consequently, we use these two properties to study the behavior of the molecules in the aggregate. ${ }^{22}$ To provide an atomistic interpretation of the experimental results, we have performed 300ns molecular dynamics (MD) calculations of Q1 and Q2 dissolved in a bilayer model of the dnllc.

\section{MATERIALS AND METHODS}

\section{Synthesis, Sample Preparation and NMR Spectra}

The synthesis of deuterated Q1 and Q2 were performed following a previously reported methodology ${ }^{12}$, only replacing 1,3-butadiene by the fully deuterated reagent, which is commercially available (Aldrich). CsDS was prepared from the reaction between decanol and sulfuric acid, followed by neutralization with $\mathrm{CsOH}$ and crystallized three times before use. DeOH$\alpha-\mathrm{d}_{2}$ was prepared by reduction of methyl decanoate ester with $\mathrm{LiAlD}_{4}$, and purified by column chromatography. All the other reagents were the highest purity commercially available and were used without further purification. The liquid crystal solution was prepared by dissolving $2.4044 \mathrm{~g}$ of CsDS, $0.5969 \mathrm{~g}$ of $\mathrm{Cs}_{2} \mathrm{SO}_{4}$ and $315 \mu \mathrm{l}$ of decanol $\left(20 \%\right.$ decanol- $\left.\alpha-\mathrm{d}_{2}\right)$ in $2.5 \mathrm{ml}$ of water $(0.1 \%$ $\mathrm{D}_{2} \mathrm{O}$ ). From this solution, three equal portions of $0.8 \mathrm{ml}$ each were separated and $5 \mathrm{mg}$ of either Q1 or Q2 were added to two of them; the third was used as reference.

All ${ }^{2} \mathrm{H}-\mathrm{NMR}$ spectra were obtained at $61.425 \mathrm{MHz}$ and $300 \mathrm{~K}$ in a Bruker Avance 400 NMR spectrometer located at the Universidad de Santiago de Chile, using a broad band inverse probe, tuned to the ${ }^{2} \mathrm{H}$ frequency. Transients were collected in $32 \mathrm{kB}$ files for a spectral window of $30 \mathrm{kHz}$. Values of $\mathrm{T}_{1}$ were measured using the T1IR pulse sequence.

\section{Molecular Dynamics}

The CsDS mesophase bilayer has been previously constructed and stabilized. ${ }^{19} 300 \mathrm{~ns}$ trajectory calculations of a $(\mathrm{N}, \mathrm{P}, \mathrm{T})$ ensemble of each system, as well as all further analysis of the simulations, were performed using the program package Gromacs v.4.0, ${ }^{23}$ running in a Supermicro cluster of blades. The charges of all species were calculated from optimized ab-initio 6-31G* structures, using the program Gaussian, ${ }^{24}$ with the option MK. ${ }^{25}$ The program $\mathrm{VMD}^{26}$ was used for the visualization of trajectories. The united atom approximation was used for all hydrogen atoms in the aliphatic chains. The GROMOS potential parameters ${ }^{27,28}$ were used for all the interactions, except for the Lennard-Jones interactions among the aliphatic chains of the amphiphiles, for which the choice was the potential of Berger. ${ }^{29}$ The Ryckaert-Belleman ${ }^{30}$ potential was used for the torsions of the aliphatic chains, and Lennard-Jones parameters for $\mathrm{Cs}^{+}$were transferred from the OPLS library. ${ }^{31,32}$ Bond lengths were constrained using LINCS $^{33}$, and SETTLE $^{34}$ was employed to restrict the structure of the SPC water molecules. ${ }^{35} \mathrm{~A} 1 \mathrm{~nm}$ cut-off was used for the Lennard-Jones potential and real space electrostatic interactions; PME was employed for longer range electrostatics. ${ }^{36,37}$ The neighbour list was updated every 10 time steps. The weak coupling algorithm of Berendsen was used to maintain the temperature at $300 \mathrm{~K}$ and the pressure at $1 \mathrm{bar}$, with time constants of $0.1 \mathrm{ps}$ and $1.0 \mathrm{ps}$ respectively. ${ }^{38}$ The time step size was $2 \mathrm{fs}$ in all simulations.

\section{RESULTS}

${ }^{2} \mathrm{H}-\mathrm{NMR}$ spectra of both molecules dissolved in the dnllc are shown in figures $2 \mathrm{~A}$ and $2 \mathrm{~B}$. Figure $2 \mathrm{C}$ is the T1IR experiment to determine $\mathrm{T}_{1}$ in sample Q1. Table 1 shows all the experimentally measured quantities. The spectrum of the mesophase in the absence of guest molecule shows only splittings from $\mathrm{DeOH}$ and HDO.
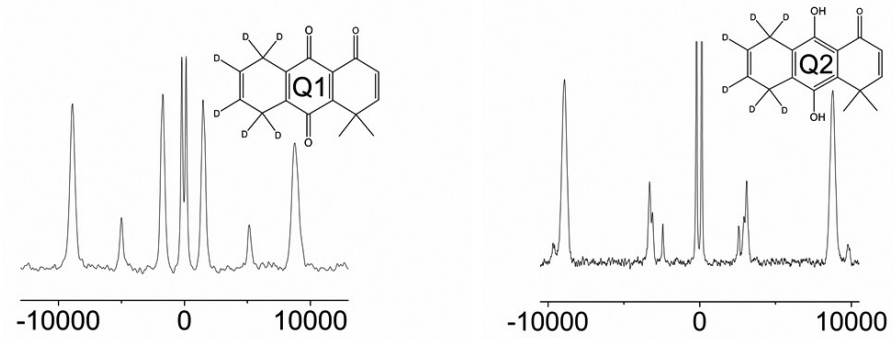

$\mathrm{Hz}$

$\mathrm{Hz}$

$2 \mathrm{C}$

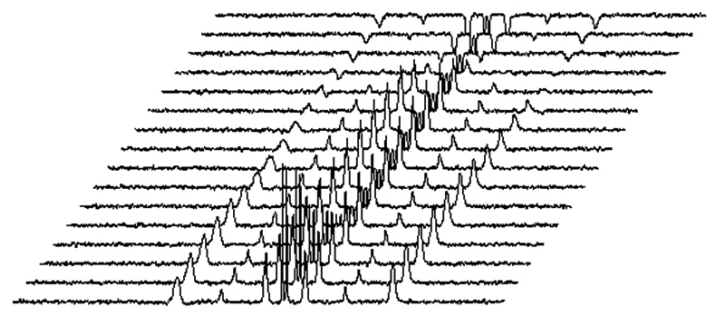

$\mathrm{Hz}$

Figure 2. Figures $2 \mathrm{~A}$ and $2 \mathrm{~B}$ are the ${ }^{2} \mathrm{H}-\mathrm{NMR}$ spectra of $\mathrm{Q} 1$ and $\mathrm{Q} 2$ dissolved in the CsDS mesophase. $2 \mathrm{C}$ is the stack plot of the T1IR experiment employed to measure $\mathrm{T}_{1}$ in sample Q1. Quadrupolar splittings were measured directly from the spectra.

Figure 3 shows a snapshot of the simulation box for the system containing Q1 and Figure 4 is the time evolution of the center of mass Z-coordinate of Q1 and Q2.

Table 1. Quadrupolar splittings $\left(\Delta v_{0}\right)$ and longitudinal relaxation times $\left(T_{1}\right)$ for all deuterium atoms in the samples, measured using ${ }^{2} \mathrm{H}-\mathrm{NMR}$. Errors in $\Delta v_{\mathrm{Q}}$ are $\pm 30 \mathrm{~Hz}$ for $\mathrm{DeOH}, \mathrm{Q} 1$, and Q2, and $\pm 3 \mathrm{~Hz}$ for DHO. Errors in $\mathrm{T}_{1}$ are $\pm 3 \mathrm{~ms}$.

\begin{tabular}{|l|c|c|c|c|}
\hline & $\begin{array}{c}\text { Pure } \\
\text { Mesophase }\end{array}$ & $\begin{array}{c}\text { Mesophase } \\
+\mathrm{Q} 1\end{array}$ & $\begin{array}{c}\text { Mesophase } \\
+\mathrm{Q} 2\end{array}$ & $\begin{array}{c}\text { Mesophase } \\
+\mathrm{Q} 2\end{array}$ \\
\hline$\Delta v_{\mathrm{Q}}(\mathrm{Hz}) \mathrm{DeOH}-\mathrm{d}_{2}$ & 16991 & 17636 & 17682 & 17682 \\
\hline$\Delta v_{\mathrm{Q}}(\mathrm{Hz}) \mathrm{HDO}$ & 330 & 340 & 348 & 348 \\
\hline$\Delta v_{\mathrm{Q}}(\mathrm{Hz}) \mathrm{CD}$ & - & 10134 & 6037 & 19410 \\
\hline$\Delta v_{\mathrm{Q}}(\mathrm{Hz}) \mathrm{CD}_{2}$ & - & 3444 & 6397 & 5002 \\
\hline $\mathrm{T}_{1}(\mathrm{~ms}) \mathrm{DeOH}-\mathrm{d}_{2}$ & 96 & 98 & 96 & 96 \\
\hline $\mathrm{T}_{1}(\mathrm{~ms}) \mathrm{HDO}$ & 492 & 451 & 456 & 456 \\
\hline $\mathrm{T}_{1}(\mathrm{~ms}) \mathrm{CD}$ & - & 15 & 10 & 9 \\
\hline $\mathrm{T}_{1}(\mathrm{~ms}) \mathrm{CD}_{2}$ & - & 12 & 11 & 11 \\
\hline
\end{tabular}

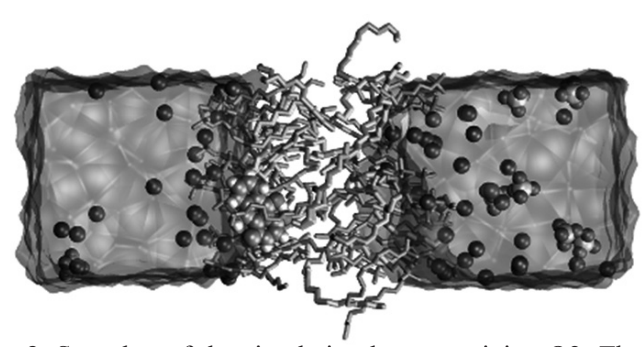

Figure 3. Snapshot of the simulation box containing Q2. The solvent is represented as a continuous light blue, sulfur is yellow, cesium is blue, oxygen is red, CsDS is orange and DeOH green. Carbon atoms from Q2 are light blue, deuterium is white and oxygen red. For a colored picture see the electronic version of the article. 


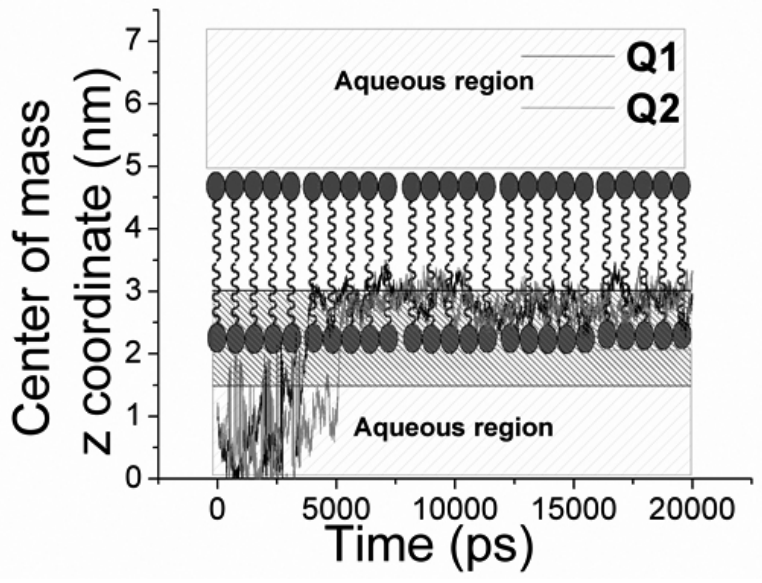

Figure 4. Center of mass Z-coordinate trajectory of Q1 and Q2 in time. Only the first $20 \mathrm{~ns}$ are displayed. The shaded region shows the zone where the sulfate head-groups move, according to the mass density plot. For a colored plot see the electronic version of the article.
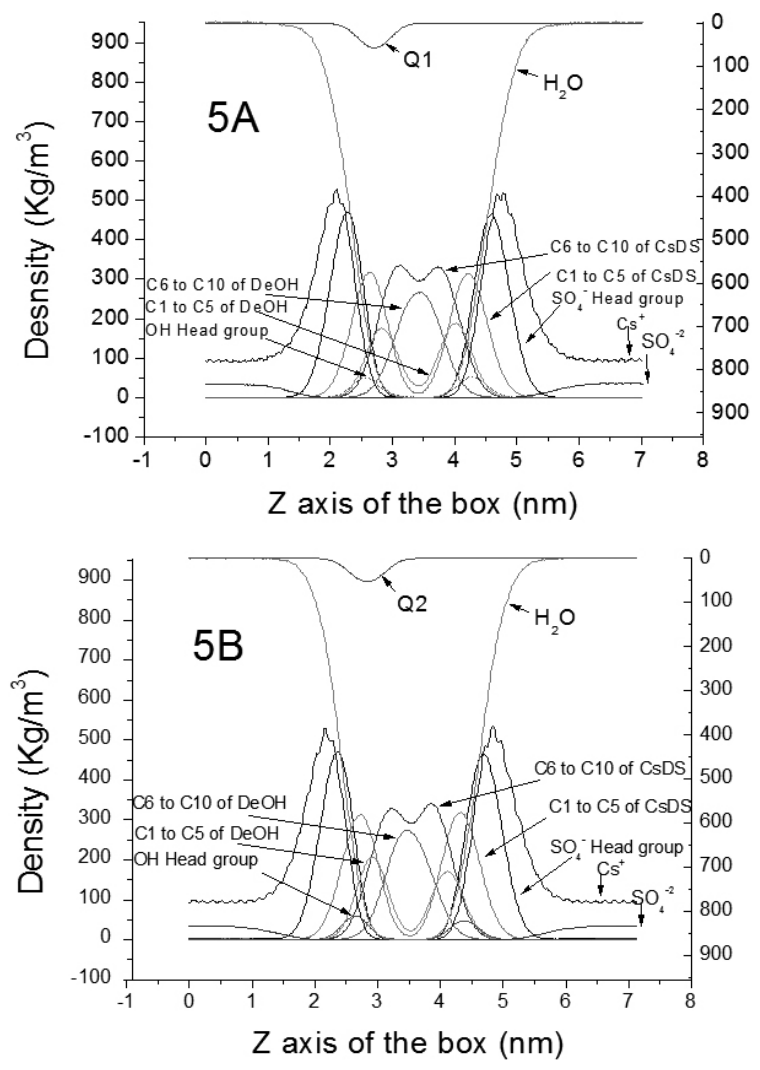

Figure 5. Mass density profiles of all components of the system along the $\mathrm{Z}$ axis of the simulation box. For a better visualization of this plot CsDS and $\mathrm{DeOH}$ have been divided into 3 fragments each, as shown in the figures. For a colored plot see the electronic version of the article.

Figure $5 \mathrm{~A}$ and $5 \mathrm{~B}$ show the calculated mass density profiles, along the $\mathrm{Z}$ axis of the box, for all the different species in the simulation. For a better visualization of these plots, CsDS and $\mathrm{DeOH}$, the two molecules that form the bilayer aggregate, were divided into 3 fragments each, as follows: the first fragment contains the sulphate or the hydroxyl head-group, the second fragment includes from $\left(\mathrm{CH}_{2}\right)_{\text {, }}$ to $\left(\mathrm{CH}_{2}\right)_{5}$, and the last fragment contains from $\left(\mathrm{CH}_{2}\right)_{6}$ to $\left(\mathrm{CH}_{3}\right)_{10}$. The identities of all plotted densities are indicated in the figures and the traces correspond to the center of mass position of each group.
To completely define the orientation of these nearly planar molecules in the bilayer, two orthogonal angles are necessary. Histograms of the angles between two selected molecular axis and the normal to the bilayer plane are shown in figures 6 and 7.
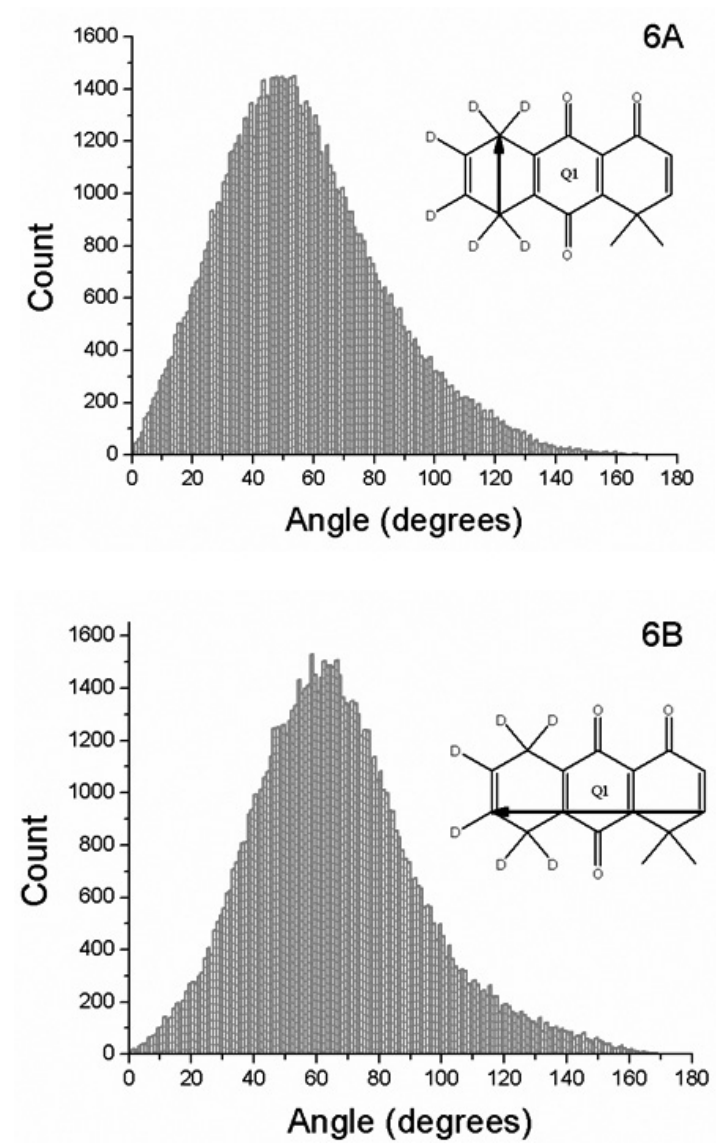

Figure 6. Histograms of the angles between the short (A) and long (B) molecular axes of Q1 and the normal to the bilayer plane, the Z-axis of the box. The label of the $\mathrm{Y}$ axis in the number of times the value appears in the distribution.

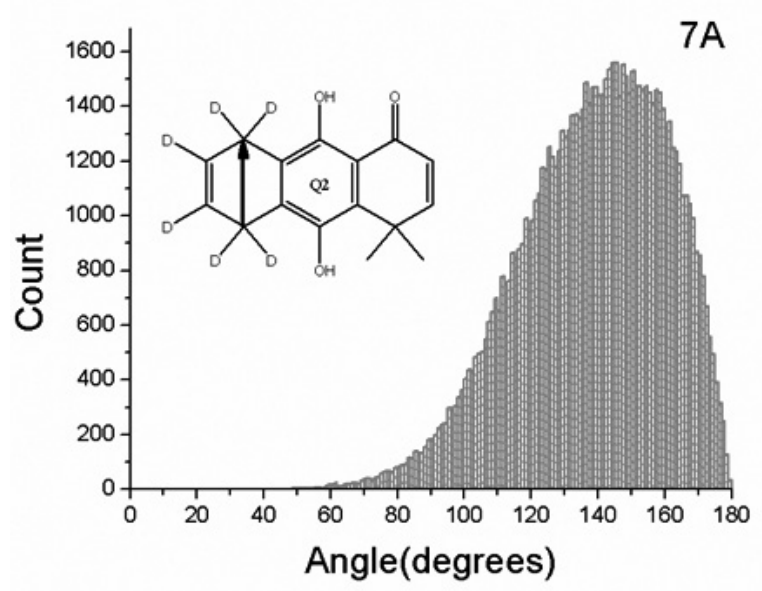




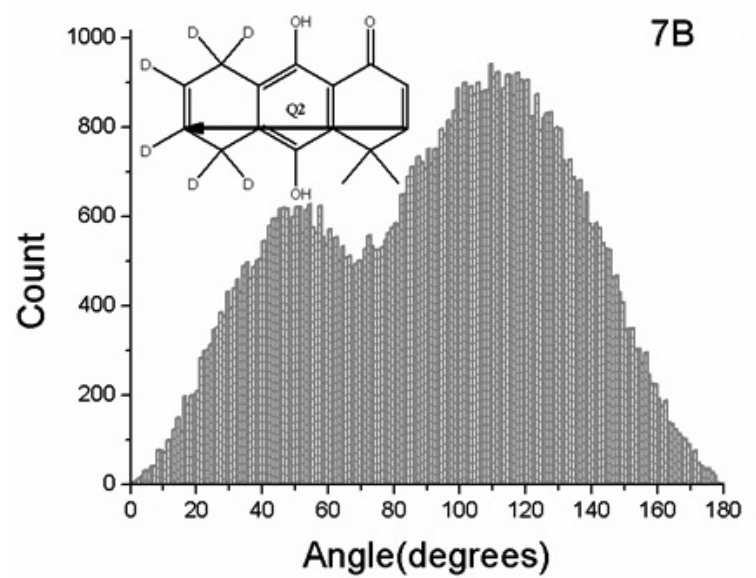

Figure 7. Histograms of the angles between the short (A) and long (B) molecular axes of Q2 and the normal to the bilayer plane, the Z-axis of the box. The label of the $\mathrm{Y}$ axis is the number of times the value appears in the distribution.

Finally, to test for the existence of H-bonds, histograms of the acceptordonor distances between the $\mathrm{OH}$ and $\mathrm{C}=\mathrm{O}$ groups of $\mathrm{Q} 1$ and $\mathrm{Q} 2$ with solvent molecules, and radial distribution functions of water molecules surrounding these groups were also calculated. The significant results are displayed in figures 8 y 9 .

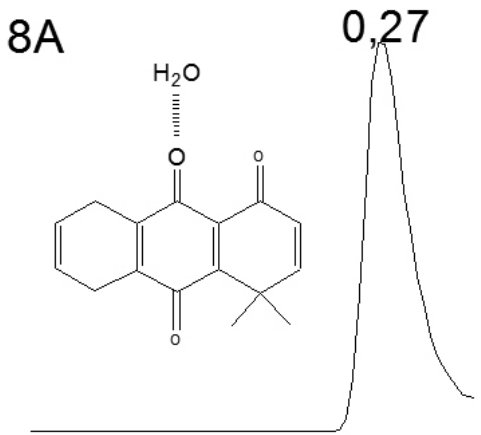

\footnotetext{
$\begin{array}{llllllllll}-0,05 & 0,00 & 0,05 & 0,10 & 0,15 & 0,20 & 0,25 & 0,30 & 0,35 & 0,40\end{array}$

Hydrogen - acceptor distance $(\mathrm{nm})$
}

\section{$8 \mathrm{~B}$}<smiles>CC1(C)C=CC(=O)c2c(O)c3c(c(O)c21)CC=CC3</smiles>

$-0,050,00 \quad 0,05 \quad 0,10 \quad 0,15 \quad 0,20 \quad 0,25 \quad 0,30 \quad 0,350,40$
Hydrogen - acceptor distance $(\mathrm{nm})$

Figure 8. Histograms for the donor-acceptor distances corresponding to the formation of $\mathrm{H}$-bond between the $\mathrm{C}=\mathrm{O}$ at $\mathrm{C} 9$ of $\mathrm{Q} 1$ and the $\mathrm{OH}$ at $\mathrm{C} 10$ of Q2 with water molecules.
Radial distribution

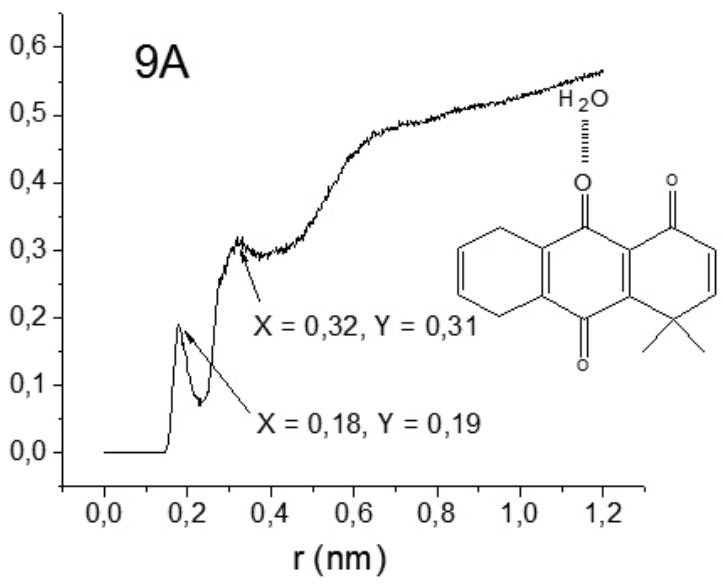

Radial distribution

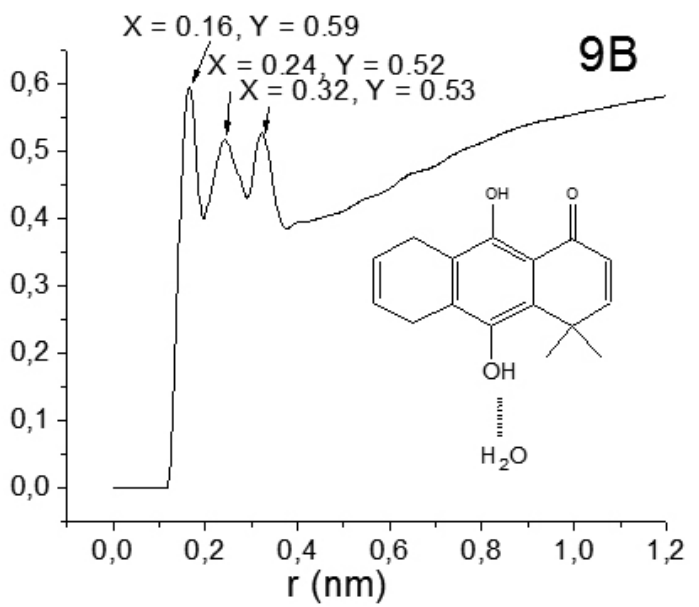

Figure 9. Radial distribution functions of water molecules surrounding the oxygen from $\mathrm{C}=\mathrm{O}$ at $\mathrm{C} 9$ in $\mathrm{Q} 1$ and the $\mathrm{OH}$ at $\mathrm{C} 10$ in $\mathrm{Q} 2$.

\section{DISCUSSION}

The spectrum from sample Q1 shows four different splittings, the largest arises from DeOH- $\alpha-\mathrm{d}_{2}$, the next two smaller splittings come from the guest molecule, assigned to the $\mathrm{CD}$ or $\mathrm{CD}_{2}$ on intensity basis, and the most intense signals but the smallest splitting arises from DHO. On the other hand, the spectrum from sample Q2 shows twelve peaks, attributable to six splittings. A simple comparison with sample Q1 allows assigning the splittings from DeOH$\alpha-\mathrm{d}_{2}$ and DHO. Since the sample without guest molecule shows only these two splittings, we propose that a strong interaction between Q2 and the mesophase components induce the formation and co-existence of a second mesophase, which is clearly observed in the NMR tube. Thus, Q2 is partitioned between these two phases but with different alignment, giving rise to two extra splitting. To make an assignment, i.e. which signals arise from the molecule dissolved in the dnllc and which from the induced mesophase, we prepared a significantly more diluted sample of Q2 (1.5mg Q2/1 $\mathrm{ml}$ of mesophase) and measured all integrals. Assuming that the amount of second phase formed is proportional to the amount of Q2 dissolved, a simple comparison between the ratios of the integrals from the different peaks, allows concluding that the largest and the smallest guest molecule splittings come from Q2 dissolved in the induced phase, since they are the only ones that decrease in relative intensity. Then, the two extra splittings, very close to each other, come from Q2 dissolved in the dnllc, the phase of interest. Table 1 also includes the splittings and $\mathrm{T}_{1}$ from Q2 dissolved in the induced phase; this value of $\mathrm{T}_{1}$ supports the proposition that these signals arise from a small molecule. 
Figure 2 shows that the quadrupole splittings from Q2 are very similar, whereas the splittings from Q1 are significantly different. Furthermore, for Q2 the splitting from the CD groups is a little smaller than the splitting from the $\mathrm{CD}_{2}$ groups, just the opposite to what is observed for $\mathrm{Q} 1$, where the splitting from the $\mathrm{CD}$ groups is much larger than the splitting from the $\mathrm{CD}_{2}$. An inspection to table 1 indicates that, despite the observed differences, the large values of $\mathrm{Dn}_{\mathrm{Q}}$ strongly suggest that Q1 and Q2 are incorporated into the aggregate. Since quadrupole splitting is a property that depends on average orientation and mobility, the origin of the observed difference is not obvious from the spectra and could arise from either of these two variables, or a combination of both. Measurements of deuterium $T_{1}$ provides information about re-orientational dynamics. In extreme narrowing conditions, $(\omega \tau<<1$ with $\omega$ the resonance frequency and $\tau$ the rotational correlation time), $T_{1}$ is nearly proportional to $\tau^{-1}$ for the corresponding C-D bond, ${ }^{22}$ and therefore proportional to mobility. Judging by the values listed in table 1, Q1, Q2 in both phases show, within the experimental error, similar values of $T_{1}$ for all nuclei. Therefore, this cannot account for the observed differences in the values of $\Delta v_{\mathrm{Q}}$. This evidence strongly suggests that Q1 and Q2 must have different average orientations inside the bilayer aggregate.

As observed from our previous work, ${ }^{19,39} \mathrm{DeOH}$ is an integral component of the bilayer and the $\alpha-\mathrm{CD}_{2}$ group is located near the interface. Consequently the observed $\Delta v_{\mathrm{O}}$ is a measurement of the dynamics of this region. An inspection to table 1 reveals that addition of either Q1 or Q2 to the mesophase increases the $\Delta v_{0}$ value of $\mathrm{DeOH}$. Considering that the orientation of the aggregate is not modified, this reveals that both molecules, when dissolved in the mesophase, increase the degree of alignment of the interface components with the magnetic field, i.e. make the interface more rigid.

The splitting from the solvent arises from HDO molecules inside the anisotropic region, which are in fast exchange with isotropic solvent molecules. Therefore the observed increase in $\Delta v_{0}$ of DHO (see Table 1) with the addition of Q1 and Q2 could arise from a decrease in the mobility of water at the interface, from modifications in their average orientation, or an increase in the amount of solvent molecules at the interface. The observed increase in $\mathrm{Dn}_{\mathrm{Q}}$ possibly arises from modifications to the dynamics of the solvent at the interface, making it more rigid. This is supported by the observed decrease in $\mathrm{T}_{1}$ from $\mathrm{DHO}$ after the addition of either Q1 or Q2, suggesting a strong interaction between the guest molecules and the solvent at the interface.

To provide a microscopic interpretation of the experimental observations, the distribution, average orientation, interactions and dynamics of Q1 and Q2, dissolved in a bilayer model of the aggregate, were examined from $300 \mathrm{~ns}$ MD trajectories. A visual inspection to randomly chosen segments of the full trajectories shows that the integrity of the bilayer is preserved along the complete simulation. All properties were calculated after the system total energy remained constant in time. As observed from figure 4, both molecules were originally positioned in the aqueous region and allowed to move freely until they reached their equilibrium location. This figure shows that Q1 and Q2 spontaneously diffuse inside the aggregate, reaching the equilibrium location between the interface and the hydrophobic core.

Figures $5 \mathrm{~A}$ and $5 \mathrm{~B}$ show the mass density profiles of all components of the systems along the z-axis of the box, including Q1 and Q2 respectively. These figures corroborate that both guest molecules are effectively associated to the aggregate, in agreement with the magnitude of the quadrupole splittings, located at the interior, near the interface, as suggested from the experimental data. From these figures we can clearly distinguish a bilayer structure made of CsDS and DeOH, with a hydrophobic core of about $10 \AA$ wide. It can be noticed that the density of $\mathrm{Cs}^{+}$ions is larger near the CsDS anionic head-groups than in the aqueous phase, introducing, as expected, a degree of electrical polarization near the interface.

In order to determine the average orientation of the molecules in the bilayer, the angles between two selected molecular axes, (one along C5 and C8 and the other along C3 and C6), and the normal to the bilayer plane, (the Z-axis of the box), were calculated from the simulations. Histograms of the distributions of both angles, for Q1 and Q2, are displayed in figures 6 and 7 respectively. These two angles are sufficient to completely describe the average orientation of the guest molecules in the bilayer. From these figures we can observe that Q1 is essentially oscillating around one fixed orientation, with both angles around $50^{\circ}$ to $70^{\circ}$. On the other hand Q2 is oriented with the short axis at about $150^{\circ}$ and the long axis display two values, $51^{\circ}$ and $107^{\circ}$. Therefore, both molecules show significantly different average orientations. The use of these average values allows to orient the molecules in the space and to conclude that the equilibrium orientations of Q1 in the bilayer is with the gem-dimethyl group pointing toward the hydrophobic core, suggesting the existence of H-bond between the $\mathrm{C}=\mathrm{O}$ at $\mathrm{C} 9$ and the solvent. On the other hand, $\mathrm{Q} 2$ appears oriented with the gem dimethyl group pointing toward the interface, suggesting the existence of $\mathrm{H}$-bond between the - $\mathrm{OH}$ group at $\mathrm{C} 10$ with solvent molecules. To test this hypothesis, histograms of donor-acceptor distances between all $\mathrm{C}=\mathrm{O}$ and $\mathrm{OH}$ groups of Q1 and Q2 with solvent molecules were calculated and the meaningful data are displayed in figures $8 \mathrm{~A}$ and $8 \mathrm{~B}$. As observed from figure 8 , only the groups pointing toward the interface, $\mathrm{C}=\mathrm{O}$ at $\mathrm{C} 9$ in $\mathrm{Q} 1$ and $\mathrm{OH}$ at $\mathrm{C} 10$ in Q2, displayed one preferential distance, the others showed very diffuse histogram. Figure 8 clearly shows preferential distances at $2.7 \AA$ and $2.6 \AA$ for Q1 and Q2 respectively. The reason for the different orientation seems to be closely related to the formation of $\mathrm{H}$-bond with solvent. In the case of Q1, the $\mathrm{H}$-bond through $\mathrm{C}=\mathrm{O}$ at $\mathrm{C} 9$ is preferred over the $\mathrm{C}=\mathrm{O}$ group at $\mathrm{C} 10$ because the gem dimethyl group presents sterical hindrance and hydrophobicity. On the other hand, in the case of $\mathrm{Q} 2$, the $\mathrm{H}$-bond with the $\mathrm{OH}$ at $\mathrm{C} 10$ is preferred over the $\mathrm{OH}$ at $\mathrm{C} 9$, because the later is already forming intramolecular $\mathrm{H}$-bond with the $\mathrm{C}=\mathrm{O}$ group at $\mathrm{C} 1$. Evidence for this arises from the ${ }^{1} \mathrm{H}-\mathrm{NMR}$ chemical shift of this proton, about $13 \mathrm{ppm}$ downfield from TMS ${ }^{12}$, where the synthesis and assignment of all ${ }^{1} \mathrm{H}-\mathrm{NMR}$ signals were done. Finally, radial distribution of solvent molecules surrounding the $\mathrm{OH}$ at $\mathrm{C} 10$ of $\mathrm{Q} 2$ and the $\mathrm{C}=\mathrm{O}$ at $\mathrm{C} 9$ of $\mathrm{Q} 1$ were calculated and displayed in figure 9. This figure reveals the presence of solvation spheres in both cases; however for Q2 it is significantly better defined, suggesting a stronger interaction with solvent molecules at the interface. This figure is also evidencing a shorter distance from the $\mathrm{OH}$ at $\mathrm{C} 10$ of Q2 and the first solvent shell, $0.16 \mathrm{~nm}$. This interaction should be strong enough to induce the appearance and co-existence of a second phase.

\section{CONCLUSIONS}

Molecular dynamics simulations have been very helpful to interpret our experimental results. Both molecules are strongly attached to the aggregate and located at the interior of the bilayer, near the interface. The inclusion of either guest molecule increases the alignment of the interface components with the magnetic field; however, they show different average orientations. The calculations predict the existence of strong $\mathrm{H}$-bonds and well defined water molecules shell structure surrounding the guest molecules. In the case of Q2, this interaction is strong enough to induce the co-existence of two phases. Furthermore, the $\mathrm{H}$-bond is also responsible for the location and orientation of the molecules in the bilayer. This may be one of the reasons for the low bioavailability of polyphenols.

\section{REFERENCES}

1. O. Aruoma, A. Murcia, J. Butler, B. Halliwell, J. Agric. Food. Chem. 41, $1880,(1993)$

2. G. Cão, E. Sofic, R. L. Prior, Free Rad. Biol. Med. 22, 749, (1997)

3. N. S. Khan, A. Ahmad, S. M. Hadi, Chemico-Biol. Interact. 125, 177 , (2000)

4. S. Azam, N. Hadi, N. U. Khan, S. M. Hadi, Toxicol. In Vitro 18, 555, (2004)

5. V. Roginsky, T. Barsukova, D. Loshadkin, E. Pliss, Chem. Phys. Lipids 125, 49, (2003)

6. P. R. Dandawate, A. C. Vyas, S. B. Padhye, M. W. Singh, J. B. Baruah, Mini-Rev. Med. Chem. 10, 436, (2010)

7. L. Garuti, M. Roberti, D. Pizzirani, Mini-Rev. Med. Chem 7, 481, (2007)

8. C. Asche, Mini-Rev. Med. Chem. 5, 449, (2005)

9. G. Powis, P. L. Appel, Biochem. Pharmacol. 29, 2567,(1980)

10. R. Araya-Maturana, B. K. Cassels, T. Delgado-Castro, J. A. Valderrama, B. E. Weiss-López, Tetrahedron 55, 637, (1999)

11. R. Araya-Maturana, T. Delgado-Castro, M. Garate, J. Ferreira, M. Pavani, H. Pessoa-Mahana, B. K. Cassels, Bioorg. Med. Chem. 10, 3057, (2002)

12. R. Araya-Maturana, W. Cardona, B. K. Cassels, T. Delgado-Castro, J. Soto-Delgado, H. Pessoa-Mahana, B. E. Weiss-López, M. Pavani, J. Ferreira, Bioorg. Med. Chem. 14, 4664, (2006)

13. $\mathrm{IC}_{50}$ of $\mathrm{Q} 1$ was provided by Prof. Dr. Jorge Ferreira, Institute of Biomedical Sciences, Molecular and Clinical Pharmacology Program, Faculty of Medicine, University of Chile, Chile, e-mail:jferreir@med. uchile.cl

14. N. Dias, C. Bailly, Biochem. Pharmacol. 70, 1, (2005)

15. N. Hail Jr., Apaoptosis 10, 687, (2005)

16. S. Fulda, L. Galluzzi, G. Kroemer, Nat. Rev. Drug Discov. 9, 447, (2010)

17. S. S. Sheu, D. Nauduri, M. W. Anders, Biochim. Biophys. Acta 1762, 256, (2006)

18. H. Ahumada, A.Vera, V. Bahamonde, R. Montecinos, R. ArayaMaturana, B. E. Weiss-López, Aust. J. Chem. 61, 968, (2008) 
19. V. Bahamonde, H. Ahumada, R. Araya-Maturana, B. E. Weiss-López, Aust. J. Chem. 63, 68, (2010)

20. H. Bensikaddour, K. Snoussi, L. Lins, F. Van Bambeke, P. M. Tulkens, R. Brasseur, E. Goormaghtigh, M. P. Mingeot-Leclercq, Biochim. Biophys. Acta 1778, 2535, (2008)

21. H. Bensikaddour, N. Fa, I Burton, M. Deleu, L. Lins, A. Schanck, R. Brasseur, Y. F. Dufrêne, E. Goormaghtigh, M. P. Mingeot-Leclercq, Biophys. J. 94, 3035, (2008)

22. A. Abragam Principles of Nuclear Magnetism, Oxford University Press: Oxford, U.K., 1985.

23. D. van der Spoel, A.R. van Buuren, E. Apol, P.J. Meulenhoff, D.P. Tieleman, A.L.T.M. Sijbers, B. Hess, K.A. Feenstra, E. Lindahl, R. van Drunen, H.J.C. Berendsen, Department of Biophisical Chemistry, University of Groningen: Groningen, The Netherlands ,2001.

24. Frisch MJ, Trucks GW, Schlegel HB, Scuseria GE, Robb M.A, Cheeseman JR, Montgomery JA, Vreven T, Kudin KN, Burant JC, Millam JM, Iyengar SS, Tomasi J, Barone V, Mennucci B, Cossi M, Scalmani G, Rega N, Petersson GA, Nakatsuji H, Hada M, Ehara M, Toyota K, Fukuda R, Hasegawa J, Ishida M, Nakajima T, Honda Y, Kitao O, Nakai H, Klene M, Li X, Knox JE, Hratchian HP, Cross JB, Adamo C, Jaramillo J, Gomperts R, Stratmann RE, Yazyev O, Austin AJ, Cammi R, Pomelli C, Ochterski JW, Ayala PY, Morokuma K, Voth GA, Salvador P, Dannenberg JJ, Zakrzewski VG, Dapprich S, Daniels AD, Strain MC, Farkas O, Malick DK, Rabuck AD, Raghavachari K, Foresman JB, Ortiz JV, Cui Q, Baboul AG, Clifford S, Cioslowski J, Stefanov BB, Liu G, Liashenko A, Piskorz P, Komaromi I, Martin RL, Fox DJ, Keith T, Al-Laham MA, Peng CY, Nanayakkara A, Challacombe M, Gill PMW, Johnson B, Chen W, Wong MW, Gonzalez C, Pople, JA, Gaussian03, Revision B.03, Gaussian, Inc., Pittsburgh, PA, 2003.

25. B. H. Besler, K. M. Merz, P. A. Kollman, J. Comput. Chem. 11, 431, (1990)
26. W. Humphrey, A. Dalk, K. Schulten, J. Mol. Graph. 14, 33, (1996)

27. W. F. van Gunsteren, H. J. C. Berendsen, Angew. Chem. Int. Ed. Engl. 29, 992, (1990)

28. W.F van Gunsteren, H. J. C.Berendsen, Biomos Nijenborgh 4, 9747AG , Groningen, The Netherlands. (1995)

29. O. Berger, O. Edholm, F. Jahnig,; Biophys. J. 72, 2002, (1997)

30. P. Ryckaert, A. Bellemans, Faraday Discuss. Chem. Soc. 66, 95, (1978)

31. W. L. Jorgensen, J. Tiradorives, J. Am. Chem. Soc. 110, 1657, (1988)

32. G. A. Kaminski, R. A. Friesner, J. Tirado-Rives, W. L. Jorgensen, J. Phys. Chem. B 105, 6474, (2001)

33. B. Hess, H. Bekker, H. J. C. Berendsen, J. G. E. M. Fraaije, J. Comput. Chem. 18, 1463, (1997)

34. S. Miyamoto, P.A. Kollman, J. Comput. Chem. 13, 952, (1992)

35. H. J. C. Berendsen, J. P. M. Postma, W. F. van Gunsteren, J. Hermans, Intermolecular Forces, B. Pullman, Ed.; The Netherlands, 331-342, 1981.

36. T. Darden, D. York, L. Pedersen, J. Chem. Phys. 98, 10089, (1993)

37. U. Essmann, L. Perera, M. L. Berkowitz, Langmuir 11, 4519, (1995)

38. H. J. C. Berendsen, J. P. M. Postma, W. F.van Gunsteren, A. Dinola, J. R. Haak, J. Chem. Phys. 81, 3684, (1984)

39. R. Montecinos, H. Ahumada, R. Araya-Maturana, R. Martinez, F. A. Olea, M. P. Aliste, D. P. Tieleman, B. E. Weiss-López, Langmuir 20, $5703,(2004)$

\section{ACKNOWLEDGEMENTS}

The authors are pleased to acknowledge financial support from FONDECYT (Grant 1095175). We thank Prof. Dr. J. Ferreira for measuring the anti-cancer activity of Q1. V.E. Bahamonde P. and M. Martinez C. acknowledge CONICYT for Doctoral Fellowships. H. Ahumada acknowledges CONICYT for a Chile Fellowship. J. Soto D. acknowledges a Post-Doctoral Fellowship from Millennium Nucleus (CILIS, ICM-P10-003-F). 